\title{
Niche separation within the mobile predator guild on marine shallow soft bottoms
}

\author{
Sverker Evans \& Bo Tallmark \\ Department of Zoology, Uppsala University, Box 561, S-751 22 Uppsala, Sweden
}

\begin{abstract}
Segregation of coexisting predatory fish and shrimp species on marine shallow soft bottoms was studied in the Gullmar Fjord (Sweden). Here, the gobiids Pomatoschistus minutus (Pallas) and $P$. microps (Krøyer) and the brown shrimp Crangon crangon L. are the most abundant epibenthic species close inshore. A temporary reduction in number of one of the species was balanced by an increased recruitment of other species in the guild, so that the overall density of epibenthic predators was kept at approximately the same level. Experimental validation of field results showed that segregation maintained by interspecific territoriality is an important mechanism regulating guild structure. We argue that competitive relations undoubtedly are of importance in maintaining structure of the epibenthic communities in Gullmar Fjord, but of minor importance for overall density of the guild.
\end{abstract}

\section{INTRODUCTION}

In coexisting species, the habitat niche generally is of greater importance than either food and time dimensions for the segregation of guild members (Schoener 1974). On uncovered or sparsely vegetated marine, shallow soft bottoms, total density and diversity of small-sized fish and shrimp species are low. Presumably this is so because predators are effective in this habitat and therefore reduce prey populations. The vegetated habitat, on the other hand, may provide sufficient structural complexity to reduce the potency of predation, and the abundance and diversity of the epibenthic community increases. Access to shelter will protect coexisting animals, and competition is likely to be of greater importance. On shallow sandy bottoms the number of niches is low and the species occupying such areas are presupposed to exploit a common pool of resources and occupy relatively broad niches with wide overlaps.

The abundant epibenthic predator guild close inshore on shallow soft bottoms in Gullmar Fjord (Swedish west coast) is dominated by the gobiid fishes Pomatoschistus minutus (Pallas) and P. microps (Krøyer), and the brown shrimp Crangon crangon L. During summer these species gather in shallow water where they coexist in much larger numbers than in deeper water (Evans \& Tallmark 1984). All 3 species behave as generalists with respect to food, and show only a small temporal segregation in peak abundances (Evans \& Tallmark 1979, 1984, Evans 1983). Due to the rich food supply provided by the benthic community, including small conspecifics, competition for food is not discernible, despite a wide overlap in dietary habits (Evans 1983, 1984). An almost continuous recruitment of new cohorts of fishes and shrimps to shallow water during summer will probably swamp the impact of potential predators. Thus, other factors must regulate the structure of the epibenthic community in the shallow soft bottom environment.

In this paper we evaluate the importance of a complex habitat for the structure of the epibenthic community in 3 shallow bays which display different physical features. We also provide experimental evidence of territoriality as an important agent for epibenthic guild structure on sandy bottoms. This leads to a discussion of the role of competitive relations and predation for the epibenthic community structure in different habitats.

\section{AREA DESCRIPTION}

The study area comprised 3 sandy bays, less than $2 \mathrm{~km}$ apart, at the mouth of Gullmar Fjord, Swedish west coast $\left(58^{\circ} 15^{\prime} \mathrm{N}, 11^{\circ} 28^{\prime} \mathrm{E}\right)$. In this area, there are virtually no tides $( \pm 5 \mathrm{~cm}$; spring tide $\pm 15 \mathrm{~cm}$ ). The 
Table 1 General description of investigation areas. HWL = high water level

\begin{tabular}{|lccc|}
\hline \multicolumn{1}{|c}{ Parameter } & Kvarnbukten Bay & Bökevik Bay & Kilviken Bay \\
\hline Area $\left(\mathrm{m}^{2}\right)$ & 36,000 & 20,500 & 6,500 \\
Depth $(\mathrm{m})$ & HWL -1 & HWL -1 & HWL - 0.5 \\
Exposedness & Moderately exposed & Moderately sheltered & Very sheltered \\
Grain size (\%) & & & \\
Pebble, granule $>2 \mathrm{~mm}$ & 6 & 7 & 1 \\
Very coarse to medium sand $0.25-2 \mathrm{~mm}$ & 9 & 21 & 9 \\
Fine to very fine sand 0.06-0.25 mm & 82 & 66 & 76 \\
Silt, clay <0.06 mm & 3 & 6 & 14 \\
Org. matter (\% d. wt.) & $0.4 \pm 0.04$ & $0.7 \pm 0.1$ & $3.3 \pm 2.6$ \\
Vegetation & - & Zostera marina & Ruppia spp. \\
No. of samples & 124 & 50 & 40 \\
\hline
\end{tabular}

physical features of the 3 bays are summarized in Table 1. As a result of different degrees of exposure, the amounts of silt and vegetation in the bays vary considerably.

\section{MATERIAL AND METHODS}

Sampling and analysis. A sampling programme was performed in the 3 adjacent bays from 1978 to 1980 using the drop-net technique (Evans \& Tallmark 1979, 1984). The size structure and species composition of the epibenthic guild in shallow water ( $\leqslant 1 \mathrm{~m}$ depth) were measured at monthly intervals. In most cases, 6 samples each of $10 \mathrm{~m}^{2}$ bottom area were collected in Kvarnbukten Bay, whereas the numbers of samples in the smaller Bökevik Bay and Kilviken Bay were 4 and 2 , respectively.

Food niche overlap. The degree of similarity in food choice between the closely related sand goby and common goby from Kilviken Bay and Kvarnbukten Bay, which contained different sets of dominant food objects, was investigated in October when both species were most abundant. About 15 individuals of each fish species with sizes between 30 and $45 \mathrm{~mm}$ were collected from each of the two sites and anaesthetized. The different food items in their stomachs were identified and counted. The total number of each prey object was summed and was expressed as a percentage of the total number of individuals of all food categories. Thus, a standard food composition was obtained for each of the 2 gobiids. The food niche overlap $\propto$ was calculated according to McArthur \& Levins (1967).

Growth. The growth of the juvenile common goby and sand goby were recorded from size frequency distributions obtained at monthly intervals.

Interference competition test. The importance of territoriality affecting the distribution of 2 of the coexisting predators on sandy bottoms, viz. brown shrimp and common goby, was investigated in the laboratory.
Aquaria of $20 \times 40 \mathrm{~cm}$ bottom area with sand as substrate were divided into 2 halves by means of a net in which a hole was punched close to the bottom. Representatives of the 2 species were introduced on each side of the net in different numerical combinations. The number of individuals was chosen so as not to exceed maximum field abundance. Mussel flesh was supplied as food in the compartment containing gobies. The hole in the net was provided with a short funnel, protruding into the goby compartment. This allowed the shrimp to migrate into the goby compartment but obstructed the migration of both species in the opposite direction. The movements of both shrimp and gobies between the 2 interconnected compartments was recorded at $6 \mathrm{~h}$ intervals. Subsequently the animals were transferred back to their original compartments and the test was repeated. Each day the test animals were replaced with newly caught ones. Aquaria with identical combinations of the 2 species but without food supply served as controls. Statistical comparisons of the distribution were made using Mann Whitney U-test.

\section{RESULTS}

\section{Species abundance and temporal distribution}

In total, 35 species of larger invertebrates and fishes were collected. Of these, 16 fishes were recorded only occasionally. Among the abundant species, the following were common on bare sand: juvenile plaice Pleuronectes platessa, sand eel Ammodytes spp., sand goby Pomatoschistus minutus, and painted goby Pomatoschistus pictus. In silty and partly vegetated habitats other species were dominant: juvenile flounder Platichtys flesus, juvenile eel Anguilla anguilla, common goby Pomatoschistus microps, black goby Gobius niger, two-spotted goby Gobiusculus flavescens, three-spined stickleback Gasterosteus aculeatus and broad-nosed pipefish Siphonostoma typhle. Sea- 

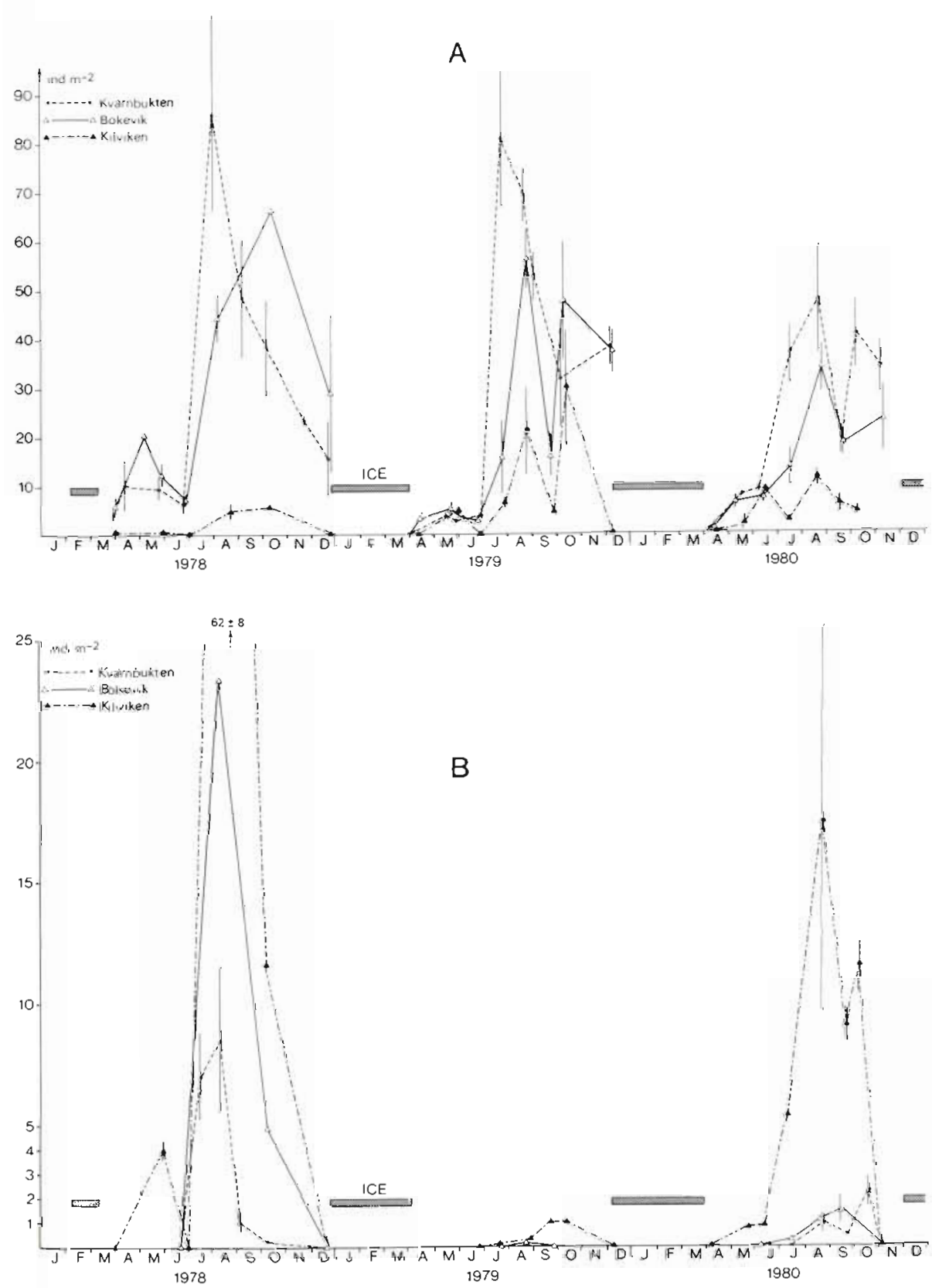

Fig. 1. Seasonal variation in abundance of (A) brown shrimp Crangon crangon, (B) common goby Pomatoschistus microps, $(\mathrm{C})$ sand goby $P$. minutus in 3 bays in Gullmar Fjord, Sweden

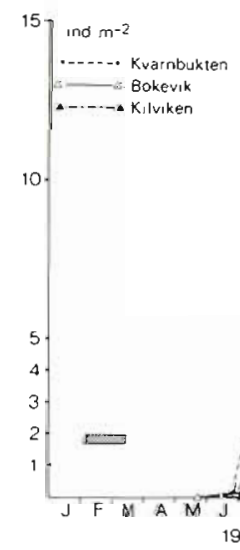

C 
sonal variations in abundance of the numerically dominant epibenthic species in the 3 bays are illustrated in Fig. 1. Both abundance and species composition of the dominant species varied strongly between the years in all 3 bays and were generally larger than differences between the bays. A peak value of about $2.5 \mathrm{~g} \mathrm{~m}^{-2}$ dry weight was recorded in August to October in all 3 yr. The brown shrimp contributed $>80 \%$ of the total biomass in Kvarnbukten Bay but only 10 to $15 \%$ in the other 2 bays. The recruitment of the different species took place synchronously in all 3 bays. The shrimp was more abundant in the unvegetated habitat with a substratum of low organic content. In all $3 \mathrm{yr}$, an abundance order of shrimp was found: Kvarnbukten $>$ Bökevik>Kilviken. Size distribution of the shrimp consistently differed between the bays throughout the investigation. In Kvarnbukten Bay a higher percentage of juveniles and a lower percentage of very large individuals were recorded, compared to the other 2 bays.

The sand goby was equally abundant in Kvarnbukten Bay and Bökevik Bay (Fig. 1). In Kilviken Bay, the density of the sand goby was considerably lower. In Bökevik and Kilviken Bay, which both support a patchy vegetation, the abundance of the common goby exceeded that in the more uniform Kvarnbukten Bay. This species was dominant in Kilviken Bay in 1978 and 1980. However, in 1979 the recruitment of common gobies to Kilviken Bay was reduced by a factor of more than 20. At the same time, the abundance of sand gobies increased by a factor of 10 at this site, compared to 1978 and 1980, while the number of shrimp increased 3fold. The absence of common gobies caused a reduction in total abundance of 60 to $90 \%$ in Kilviken Bay, compared to 10 to $20 \%$ in Kvarnbukten and Bökevik Bay.
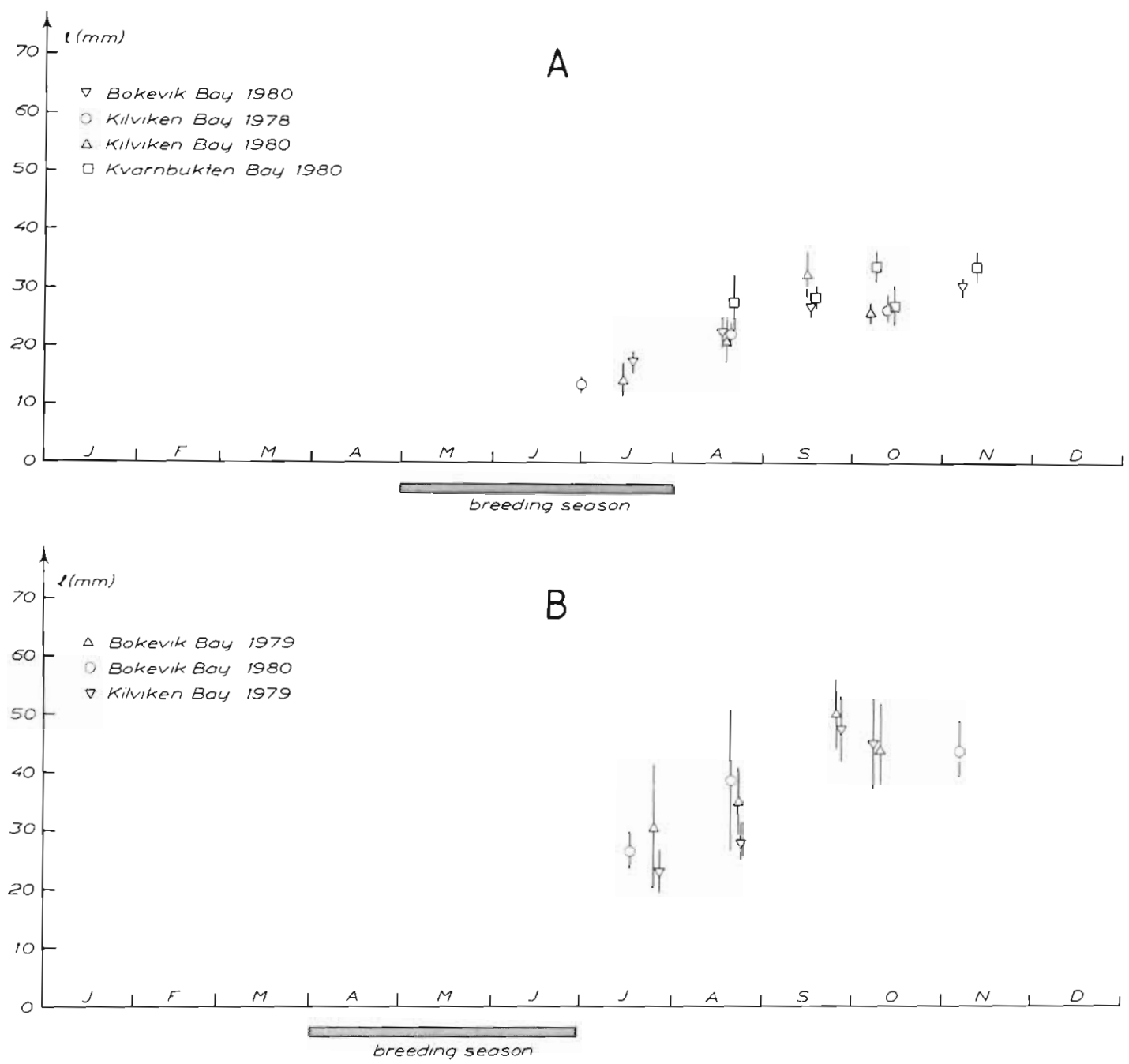

Fig. 2. Growth of 0 -group common goby Pomatoschistus microps (A) and sand goby $P$. minutus (B) in 3 bays in Gullmar Fjord. Mean size \pm SD, pooled at monthly intervals 


\section{Growth}

Growth rates of juvenile sand gobies and juvenile common gobies were assessed from size frequency distributions in the different bays (Fig. 2). Once the 0 group appeared, the size frequency distribution of the entire population became bimodal. However, the growth of both species was rapid and about 1 mo after the first appearance of young specimens, the cohort was mixed with older individuals so the different year classes became difficult to recognize. Because of the extended breeding season, changes in mean size of the 0 -group with time was influenced by the successive influx of new juveniles to the population. The actual growth rate was thus likely to be higher than suggested by the mean size determinations. However, the growth rate of the common goby was similar in Danish waters (Muus 1967), and also agreed with that reported from the English Channel (Fouda \& Miller 1981). In the sand goby, monthly growth was between 5 and $10 \mathrm{~mm}$ from July to September, which was somewhat lower than estimated by Swedmark (1957). In Kvarnbukten Bay the growth rates of both gobiids were lower than those found in Kilviken Bay, with the growth rates from Bökevik Bay as an intermediate.

\section{Food}

Stomach contents and food-niche overlaps of sand goby and common goby from the 2 sites are presented in Table 2. In Kilviken Bay, chironomids (Chironomus spp.) and the amphipod Corophium volutator made up the bulk of the food of both fish species. In Kvarnbukten Bay, harpacticoid copoepods, which also move actively upon the sandy surface, were totally dominant by number in the stomachs of both fish species. Consequently, food-niche overlaps for the gobiids were close to unity in both habitats.

\section{Interference competition test}

Results of interference competition experiments are presented in Table 3. Experiments run over $24 \mathrm{~h}$ periods showed that the distribution of animals remained fairly stable after 4 to $6 \mathrm{~h}$. When food was supplied to the sand gobies, the number of shrimp penetrating into the goby compartment decreased significantly as the number of gobies increased $(\mathrm{p}<0.001$ for all numerical combinations of gobies, Mann Whitney $U$ test). On the other hand, when no food was offered to the gobies, the number of intruding shrimp was positively correlated to the number of gobies present. This is explained by the higher activity of the gobies caused by crowding and food shortage, and this disturbed the shrimp. Similarly, when the shrimp initially had access to the food they prevented the gobies intruding into the food compartment. Thus, the presence of 1 guild member significantly affected the distribution of the other, the number of animals intruding being negatively correlated to the number of animals already present. This implies that there is an upper limit of crowding, regulated by means of aggressive behaviour.

\section{DISCUSSION}

In Gullmar Fjord, the shrimp and 2 gobiid species are adapted to slightly different habitats. The common goby Pomatoschistus microps was found in the innermost parts of the littoral while the sand goby Pomatoschistus minutus was uniformly distributed from high water level (HWL) to $10 \mathrm{~m}$ depth (Evans \& Tallmark 1984). This agrees with observations from the Irish Sea made by Jones \& Miller (1966). They found that the nests of the common goby almost were entirely confined to very shallow shore pools. The eggs of the sand goby, on the other hand, occurred both close inshore and in deeper water (Fonds 1973, Hesthagen 1977,

Table 2. Percentage standard composition of stomach contents of sand goby Pomatoschistus minutus and common goby $P$ microps in Kilviken Bay (mud) and Kvarnbukten Bay (sand). $\alpha_{\mathrm{i} j}$ denotes food-niche overlap of sand goby on common goby, and $\alpha_{\mathrm{ji}}$ overlap of common goby on sand goby

\begin{tabular}{|lccrc|}
\hline \multicolumn{1}{c}{ Prey object } & \multicolumn{2}{c}{$\begin{array}{c}\text { Kilviken Bay } \\
\text { Common goby }\end{array}$} & Sand goby & Kvarnbukten Bay \\
Common goby
\end{tabular}


Table 3. Frequency distribution of number of shrimp and gobies migrating into the opposite compartment. Number of gobies 0.5 and 10 ; number of shrimp 5

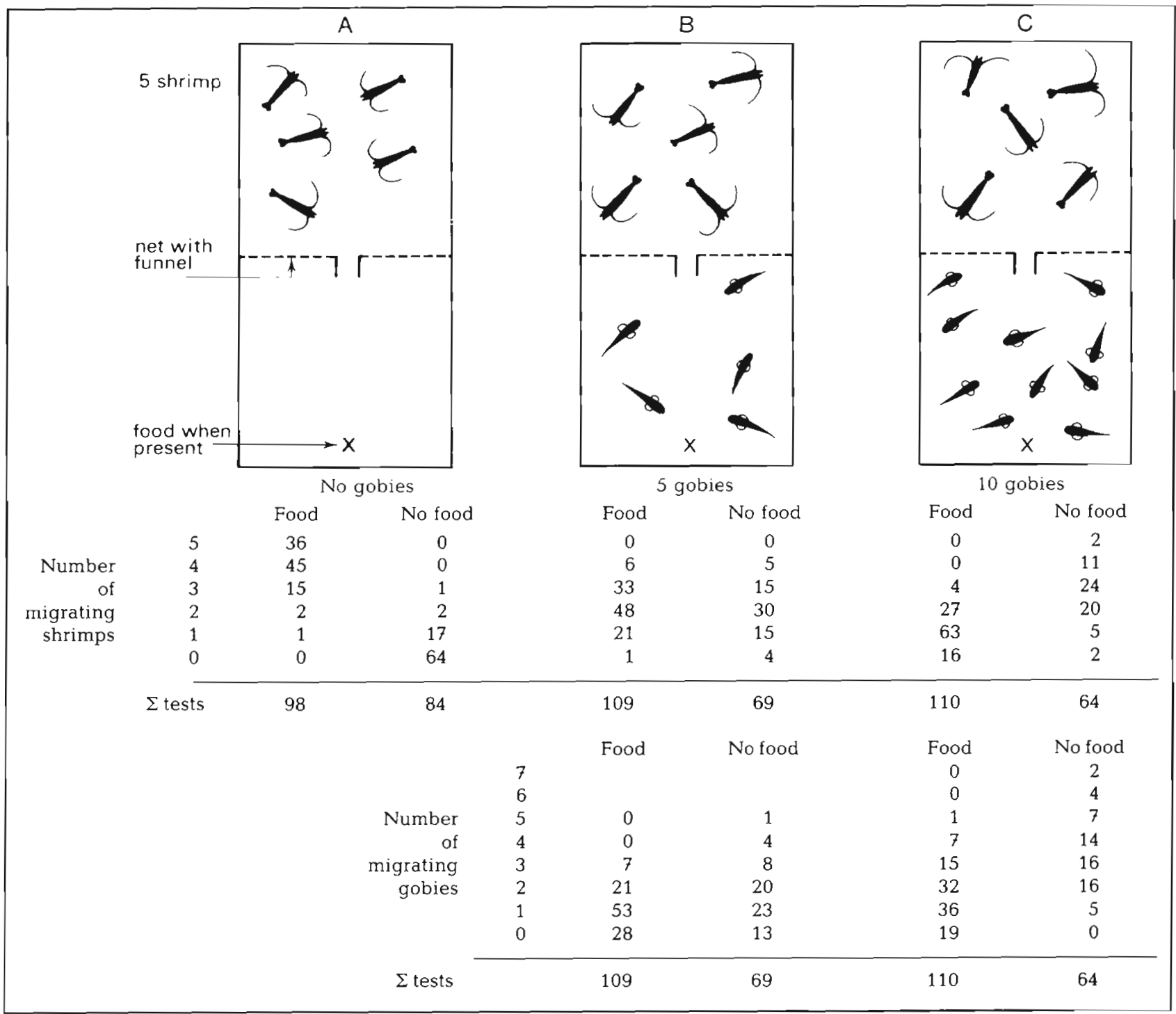

Evans \& Tallmark 1979). According to experimental findings by Fonds \& van Buurt (1974), temperature and salinity boundaries for the development of gobiid eggs will influence gobiid distribution. Eggs of the common goby survived within a narrow temperature range (15 to $20^{\circ} \mathrm{C}$ ), compared to the eggs of the sand goby ( 10 to $20^{\circ} \mathrm{C}$ ). Furthermore, eggs of the common goby survived well in a wider salinity range ( 5 to $35 \%$ ), than those of the sand goby (15 to $35 \%$ ). In Kvarnbukten Bay the sand goby bred 1 mo earlier than the common goby (Evans \& Tallmark 1984), which also supports the results of Fonds \& van Buurt (1974). In Gullmar Fjord a slight temporal and spatial segregation of the 2 gobiids may thus occur which should reduce competition for suitable nestsites.

The range of the sand goby population from the shore line down to at least $10 \mathrm{~m}$ depth will allow a considerable population size in shallow water, and lead to the littoral becoming occupied each year. This is in contrast to the common goby which breeds only in shallow water and thus is much more susceptible to physical disturbances than are the other 2 species. In Kilviken Bay, the common goby normally contributed $50 \%$ to the total abundance of the epibenthic guild. In 1979, a failure of this species to appear coincided with a heavy invasion of sand gobies to this habitat (Fig. 1). The brown shrimp too, increased in abundance in Kilviken Bay that year, and it is likely that these events are related. In Kvarnbukten and Kilviken Bay, the lacking recruitment of the common goby did not affect the abundance of the other 2 species. However, the common goby was normally relatively rare in the 
unvegetated habitat and did not contribute significantly to the total abundance. On the other hand, the common goby seemed to have a great impact on the dispersion of the sand goby and brown shrimp populations in the vegetated habitat.

The abundance of fish in the muddy and vegetated habitats, which provide prey refuges, was always higher than on clean sand. In the unvegetated habitat, refuges are lacking and predation keeps the competing species at relatively low densities so that competitive exclusion does not occur. This is in agreement with Connell (1975), who argued that predation is of primary importance for community structure unless reduced by other factors. Therefore, interference competition for space rather than for food resources should be important among motile animals in seagrass meadows.

The structure of the shallow-water community is in part regulated by the environment, which is characterized by large fluctuations in physical variables. However, for consumer populations, the dependence upon other organisms for food probably is more important as regulator than the physical environment, which can be avoided when unfavourable. The presence of abundant opportunistic epibenthic omnivores may result in a predator-regulated community. However, epibenthic predators do not crop infauna to an extent sufficient to reduce infaunal abundance or species composition (Berge \& Hesthagen 1981, Evans 1983, 1984, Quammen 1984). On uncovered or sparsely vegetated sandy bottoms such as Kvarnbukten Bay, total density and diversity of the epibenthic community are low. This presumably is because predators are more effective in this habitat and therefore reduce the populations, and this process reduces the impact of competition. An exceptional case is the brown shrimp which subsists in large numbers on open bottoms. The impact

Table 4. Relative differences in life history strategies of sand goby, common goby and brown shrimp, and their consequences for population dynamics

\begin{tabular}{|c|c|c|c|}
\hline & $\begin{array}{l}\text { Sand } \\
\text { goby }\end{array}$ & $\begin{array}{l}\text { Common } \\
\text { goby }\end{array}$ & $\begin{array}{l}\text { Brown } \\
\text { shrimp }\end{array}$ \\
\hline Life $\operatorname{span}(y)$ & $2-(3)$ & $1-(2)$ & $2-3$ \\
\hline Iteroparity & yes? & no? & yes \\
\hline $\begin{array}{l}\text { Spawning grounds } \\
\text { (depth } \mathrm{m} \text { ) }\end{array}$ & $0->10$ & $0-1$ & $>10$ \\
\hline $\begin{array}{l}\text { Susceptibility to } \\
\text { physical disturbances }\end{array}$ & less & more & less \\
\hline Spawning period & Mar-Jul & Apr-Aug & $\underset{\text { Jul-Aug }}{\text { Apr }}$ \\
\hline Population dynamics & $\begin{array}{l}\text { low, } \\
\text { stable }\end{array}$ & $\begin{array}{l}\text { high, } \\
\text { fluct. }\end{array}$ & $\begin{array}{l}\text { high, } \\
\text { stable }\end{array}$ \\
\hline
\end{tabular}

of predators, however, may be swamped out as a result of large settling peaks within restricted areas. In vegetated habitats such as Bökevik Bay and Kilviken Bay, access to shelter may significantly reduce the potency of predation (Berglund \& Bengtsson 1981). Since the high production of food organisms in shallow water probably will further reduce exploitation competition, interference competition is likely to be of greater importance. Thus, the habitat niche is predicted to be of greater importance for the segregation of coexisting small-sized predators in shallow water. These organisms can survive the physical stresses in the littoral. However, they are of course susceptible to biotic mortality agents, such as predation by larger fishes. Predators such as weevers, bullheads, larger flatfish and gadoids are more numerous in deeper water. The large numbers of juvenile gobiids leaving the littoral in autumn and the low numbers of returning survivors arriving from deeper water in spring suggest that predation is one of the main causes of population reduction during winter

\section{CONCLUSIONS}

We suggest that the epibenthic community studied is strongly influenced by intra-guild predation close inshore during summer, and by predation from larger species not belonging to the guild in deeper water during winter. Competition for space and food undoubtedly is of importance for community structure, but normally is only of minor importance for population sizes of guild members. The opportunistic behaviour of the epibenthic predators make it possible for these species to exploit resources available when one or several of them temporarily is reduced in number or even absent. The brown shrimp and the 2 gobiid species have evolved adaptations to survive the rigours of the shallow water environment. However, their life history tactics may differ (Table 4), which may lower the probability of competitive exclusion.

Acknowledgements. We thank J. Gray, G. Gezelius and S. Ulfstrand for valuable comments on the manuscript, and $\mathrm{A}$. Bengtsson and $C$. Brodin for assistance in the experimental work. The work was conducted at Klubban Biological Station and we are grateful to G. Gezelius for providing excellent working conditions. The study was supported by grants from the Swedish Natural Science Council.

\section{LITERATURE CITED}

Berge, J. A., Hesthagen, I. H. (1981). Effects of epibenthic macropredators on community structure in an eutrophicated shallow water area, with special reference to food consumption by the common goby Pomatoschistus microps. Kieler Meeresforsch., Sonderh. 5: 462-470 
Berglund, A., Bengtsson, J. (1981). Biotic and abiotic factors determining the distribution of two prawn species: Palaemon adspersus and P. squilla. Oecologia (Berl.) 49: 300-304

Connell, J. (1975). Some mechanisms producing structure in natural communities: a model and evidence from field experiments. In: Cody, L., Diamond, J. M. (ed.) Ecology and evolution of communities. Belknap Press, Cambridge, p. $460-490$

Evans, S., Tallmark, B. (1979). A modified drop-net method for sampling mobile epifauna on marine shallow sandy bottoms. Holarct. Ecol. 2: 58-64

Evans, S., Tallmark, B. (1984). Seasonal dynamics of small vagile predators on a marine shallow soft bottom. Holarct. Ecol. 7: 138-148

Evans, S. (1983). Production, predation and food niche segregation in a marine shallow soft-bottom community. Mar. Ecol. Prog. Ser. 10: 147-157

Evans, S. (1984). Energy budgets and predation impact of dominant epibenthic carnivores on a shallow soft bottom community at the Swedish west coast. Estuar. coast. Shelf Sci. 18: 651-673

Fonds, M., van Buurt, G. (1974). The influence of temperature and salinity on development and survival of goby eggs (Pisces, Gobiidae), Hydrobiol. Bull. Amsterdam 8: 110-116

Fonds, M. (1973). Sand gobies in the Dutch Wadden Sea
(Promatoschistus, Gobiidae, Pisces). Neth. J. Sea Res. 6: $417-478$

Fouda, M. M., Miller, P. J. (1981). Age and growth of the common goby, Pomatoschistus microps, on the south coast of England. Estuar. coast. Shelf Sci. 12: 121-129

Hesthagen, I. (1977). Migrations, breeding, and growth in Pomatoschistus minutus (Pallas) (Pisces, Gobiidae) in Oslofjorden, Norway. Sarsia 63: 17-26

Jones, D., Miller, P. J. (1966). Seasonal migrations of the common goby Pomatoschistus microps (Kroyer), in Morecambe Bay and elsewhere. Hydrobiologia 27 : 515-528

McArthur, R., Levins, R. (1967). The limiting similarity, convergence, and divergence of coexisting species. Am. Nat. 101: $377-385$

Quammen, M. L. (1984). Predation by shorebirds, fish, and crabs on invertebrates in intertidal mudflats: an experimental test. Ecology 65: 529-537

Muus, B. (1967). The fauna of Danish estuaries and lagoons. Meddr Danm. Fisk.-og Havunders. N. S. 5: 1-316

Schoener, T. W. (1974a). Resource partitioning in ecological communities. Science 185: 27-39

Swedmark, M. (1957), Variation de la croissance et de la taille dans differentes populations du teleosteen Gobius minutus. Coll. Int. Biol. Mar. Stat. Roscoff. l'Anée Biol. 3: $163-170$

This paper was presented by Professor J. Gray; it was accepted for printing on March 20, 1985 